\title{
RANCANG BANGUN SISTEM KOMUNIKASI ANTAR UAV UNTUK FORMASI UAV
}

\author{
Rendra Dwi Firmansyah ${ }^{1}$, Esa Apriaskar ${ }^{2}$, Tika Erna Putri ${ }^{3}$ \\ ${ }^{1}$ Balai Pengembangan Instrumentasi, Lembaga Ilmu Pengetahuan Indonesia \\ ${ }^{2}$ Teknik Elektro, Fakultas Teknik, Universitas Negeri Semarang \\ ${ }^{3}$ Departemen Teknik Elektro dan Informatika, Sekolah Vokasi, Universitas Gadjah Mada \\ firman.1412@gmail.com¹, esa.apriaskar@mail.unnes.ac.id ${ }^{2}$, tika.erna.p@ugm.ac.id ${ }^{3}$
}

\begin{abstract}
UAV formation is one of techology development in UAV world. The UAV formation can be utilized in various fields including agriculture, mapping and defense security (HANKAM). Communication is one of the important components in making UAV formations. To make UAV formations, position and direction data (AHRS) from each UAV will be sent to other UAVs so that when forming UAV formation, no collisions occur between UAVs. This study uses a star topology like the one on a computer network. This method involves two or more UAVs, both of which will exchange data. In this study the data sent is in the form of a dummy data package using the xbee module. The purpose of this study is the initial model of communication between UAVs which can later be developed into more complex communication models for many UAVs. The results obtained in the form of maximum communication distance between UAVs is $50 \mathrm{~m}$ and the recommended optimal distance is 10-20m.
\end{abstract}

Keywords : UAV, Communication, UAV Formation, Xbee

\begin{abstract}
Intisari - Formasi UAV merupakan salah satu perkembangan teknologi di bidang UAV. Formasi UAV ini dapat dimanfaatkan di berbagai bidang antara lain pertanian, pemetaan, dan pertahanan keamanan (HANKAM). Komunikasi merupakan salah satu komponen penting dalam pembuatan formasi UAV. Untuk membuat formasi UAV dibutuhkan data posisi dan arah (AHRS) dari masing-masing UAV yang akan dikirimkan ke UAV yang lain sehingga pada saat pembentukan formasi UAV, tidak terjadi tabrakan antar UAV. Penelitian ini menggunakan topologi star seperti yang ada pada jaringan komputer. Metode ini melibatkan dua atau lebih UAV yang keduanya akan saling bertukar data. Pada penelitian ini data yang dikirimkan berupa paket data dummy menggunakan modul xbee. Tujuan dari penelitian ini adalah model awal komunikasi antar UAV yang nantinya dapat dikembangkan menjadi model komunikasi yang lebih kompleks untuk banyak UAV. Hasil yang didapatkan berupa jarak maksimal komunikasi antar UAV adalah 50m dan jarak optimal yang disarankan adalah 10$20 \mathrm{~m}$.
\end{abstract}

Kata kunci : UAV,Komunikasi, Formasi UAV, Xbee

\section{PENDAHULUAN}

Formasi UAV merupakan salah satu perkembangan teknologi di bidang UAV. Formasi UAV ini dapat dimanfaatkan di berbagai bidang antara lain pertanian, pemetaan, dan pertahanan keamanan (HANKAM). Bidang pertanian dapat memanfaatkan UAV untuk melakukan penyemprotan pestisida atau penyebaran bibit yang akan lebih efektif menggunakan formasi UAV dalam prosesnya karena waktunya akan terpangkas lebih cepat. Bidang pemetaan, kegiatan pemetaan akan jauh lebih cepat jika menggunakan formasi UAV karena dapat mengambil gambar di beberapa titik sekaligus. Bidang HANKAM dapat memanfaatkan formasi untuk pemantauan wilayang musuh atau perbatasan dalam satu waktu.

Komunikasi merupakan salah satu komponen penting dalam pembuatan formasi UAV. Untuk membuat formasi UAV dibutuhkan data posisi dan arah yang disebut Attitude and heading reference systems (AHRS) dari masingmasing UAV yang akan dikirimkan ke UAV yang lain sehingga pada saat pembentukan formasi UAV, tidak terjadi tabrakan antar anggota formasi. Untuk melakukan distribusi data ini diperlukan sebuah metode komunikasi yang dapat mengirimkan dan menerima data antar UAV. Distribusi data ini dapat dilakukan dengan baik jika terjadi komunikasi yang baik antar UAV. Komunikasi yang baik yang dimaksud adalah data yang dikirim oleh satu UAV dapat diterima dengan lengkap oleh UAV yang lain secara realtime. Untuk itu diperlukan penelitian tentang komunikasi data antar UAV sebagai awal pembuatan formasi UAV.

Referensi [1] melakukan penelitian tentang penggunaan standar komunikasi IEEE 802.11n dan 802.11ac. Penelitian ini ada beberapa tahap yaitu konfigurasi IEEE $802.11 \mathrm{n}$. Tahap kedua implementasi 802.11ac yang mempunyai jangkauan lebih jauh. Tahap ketiga menganalisis jika standar tersebut diimplemetasikan pada banyak UAV. Penelitian ini menunjukkan bahwa komunikasi dapat berjalan dengan baik menggunakan standar 802.11n dan struktur mesh. Model ini disarankan sangat baik untuk formasi UAV.

Penelitian tentang komunikasi yang efisien untuk UAV juga dilakukan oleh [2]. Penelitian ini menunjukkan betapa pentingnya komunikasi UAV. Dalam penelitian ini keamanan komunikasi UAV sangat penting karena jika komunikasi menggunakan jalur yang kurang aman, data yang dikirim bias disadap atau malah dimanipulasi. Sehingga dibutuhkan sebuah jalur komunikasi yang terpercaya dan aman. Penelitian ini mengusulkan Mobile Ad hoc Networks (MANETs) sebagai solusi. MANETs merupakan topologi dynamic otomatis. MANETs dan UAV mempunyai kesamaan karakteristik sehingga sebuah kelompok UAV dapat dianggap sebagai MANETs. Menurut penelitian ini Trust-based MANET dapat digunakan sebagai salah satu metode komunikasi yang aman untuk UAV.

Referensi [3] melakukan penelitian tentang komunikasi data UAV yang saat ini menjadi isu penting dalam dunia pesawat tanpa awak. Pada penelitian ini diusulkan sebuah 
model dan metode komunikasi data yang real time pada UAV. Memanfaatkan teori wireless sensor networks (WSNs) penelitian ini mengusulkan topologi small-world network dan menggunakan algoritma koloni semut untuk update dan pengiriman data. Hasil dari penelitian ini metode yang diusulkan sudah dapat bekerja dengan baik pada update router tetapi masih banyak butuh perbaikan untuk menghasilkan pengiriman data yang realtime.

Referensi [4] melakukan penelitian tentang multichannel long-range communication link untuk UAV. Sasaran dari penelitian ini adalah pelayanan yang tinggi, bandwith yang sedang dan dengan harga yang terjangkau. Metode ini memanfaatkan satu UAV yang digunakan sebagai relai komunikasi yang menyediakan telemetri dan telecommand dan downlink untuk video. Sistem ini dapat diimplementasikan pada UAV ukuran sedang. Sistem ini menggunakan active circular array of linearly polarized circular patch.

Referensi [5] menyatakan bahwa komunikasi UAV mempunyai peranan penting dalam UAV. Penelitian ini focus pada keamanan pada layer fisik pada komunikasi UAV. Metode yang ditawarkan pada penelitian ini adalah memanfaatkan UAV trajectory dan daya kirim pada bidang datar. Algoritma iterative digunakan untuk mengatasi masalah efisiensi berdasarkan the block coordinate descent and successive convex optimization methods. Hasil numeric pada penelitian ini menunjukkan bahwa metode yang diusulkan dapat meningkatkan secrecy rate dari system komunikasi UAV.

Referensi [6] juga melakukan penelitian tentang komunikasi UAV. Penelitian ini fokus menyelidiki bagaimana cara memastikan bahwa komunikasi data dari remote sampai secara bersamaan pada beberapa UAV atau formasi UAV. Masalah pada penelitian ini diformulasikan sebagai mixed-integer programming dengan tujuan memaksimalkan sinyal minimum pada interference pluse noise ratio untuk semua UAV. Metode yang ditawarkan pada penelitian ini adalam melakukan penjadwalaan timefrequency block. Setelah dilakukan simulasi, hasil dari metode ini menunjukkan hasil yang sangat efektif dengan beberapa konfigurasi parameter.

\section{METODOLOGI}

Penelitian ini berfokus pada perancangan model komunikasi yang optimal untuk pertukaran data antar UAV. Komunikasi yang telah dirancang akan diuji coba dengan mencari jarak maksimal dan jarak optimal antara satu UAV dengan UAV lainnya. Penelitian ini memanfaatkan jalur komunikasi $2.4 \mathrm{Ghz}$ yang banyak digunakan oleh perangkat wifi. Penggunaan jalur ini beresiko terinterferensi gangguan dari sinyal lain karena banyaknya pengguna. Namun dengan menggunakan perangkat xbee sebagai modul komunikasi dapat mengatasi masalah tersebut. Alat dan bahan yang digunakan dalam penelitian ini ditunjukkan oleh tabel Tabel 1.

Tabel 1. Alat dan Bahan

\begin{tabular}{|l|l|}
\hline No & Alat dan Bahan \\
\hline 1 & Modul Xbee S2 PRO \\
\hline 2 & Arduino UNO \\
\hline 3 & Xbee Shield \\
\hline 4 & Kabel \\
\hline
\end{tabular}

Komunikasi yang dirancang mengambil model formasi leader-follower. Model formasi ini menjadikan satu UAV sebagai pusat komunikasi yang mengirimkan dan menerima data dan perintah. UAV yang lain akan bertindak sebagai follower yang menerima perintah dari leader dan menjalankannya. Komunikasi ini memanfaatkan topologi star yang sering digunakan di bidang jaringan computer. Kelebihan dari topologi ini adalah jika ada salah satu UAV yang mengalami kerusakan maka tidak akan mengganggu komunikasi antar UAV yang lainnya. Rancangan topologi star yang diusulkan pada komunikasi antar UAV ditunjukkan oleh Gambar 1.

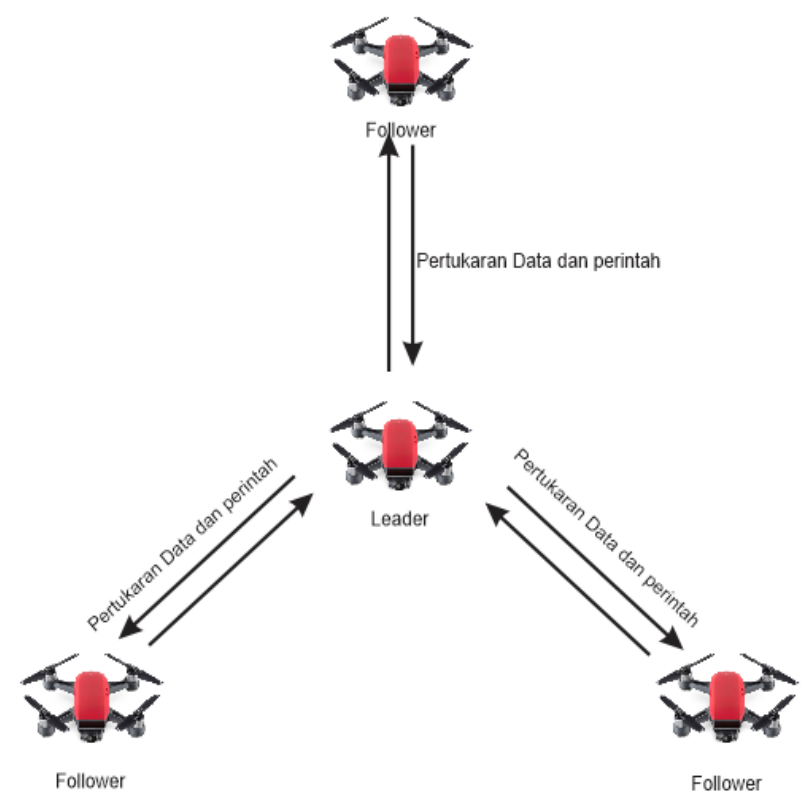

Gambar 1. Topologi Komunikasi Antar UAV

Pengambilan data dilakukan dengan cara UAV 1 mengirimkan 5 paket data ke UAV 2 lalu diukur kekuatan sinyal dan tingkat keberhasilan pengiriman data tersebut. Lalu setelah itu jarak antar UAV akan ditambah sampai data yang dikirim tidak terkirim atau sinyal sudah hilang yang artinya jarak tersebut adalah jarak maksimal yang dapat dilakukan pertukaran data. Metode pengambilan data ditunjukkan oleh Gambar 2.

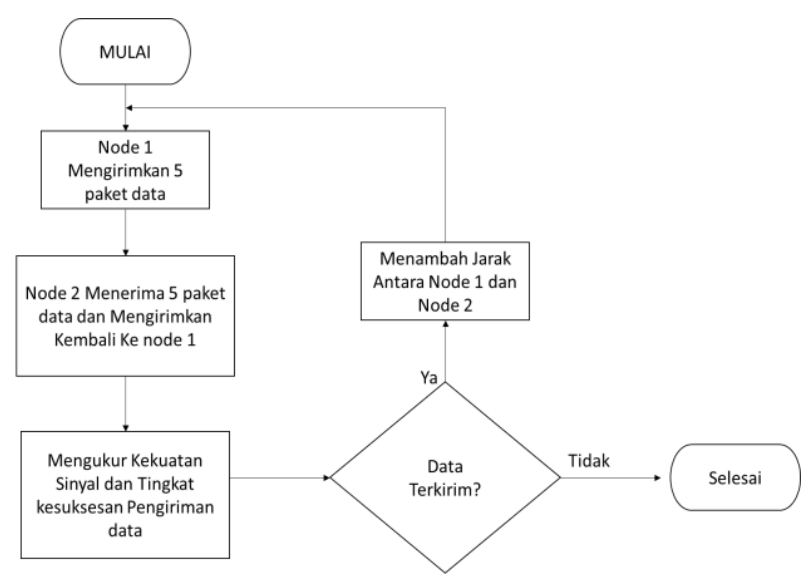

Gambar 2. Metode Pengumpulan Data 
Pengukuran sinyal dan tingkat keberhasilan pengiriman data dilakukan dengan menggunakan perangkat lunak range test yang telah disediakan oleh XCTU. Penggunaan perangkat lunak ini sangat membantu dalam pengambilan data karena dengan menggunakan perangkat lunak ini dapat diatur paket data yang dikirimkan dan jumlah paketnya sehingga dapat disesuaikan dengan format data yang akan digunakan dalam formasi UAV. Gambar 3. menunjukkan perangkat lunak range test dari XCTU.

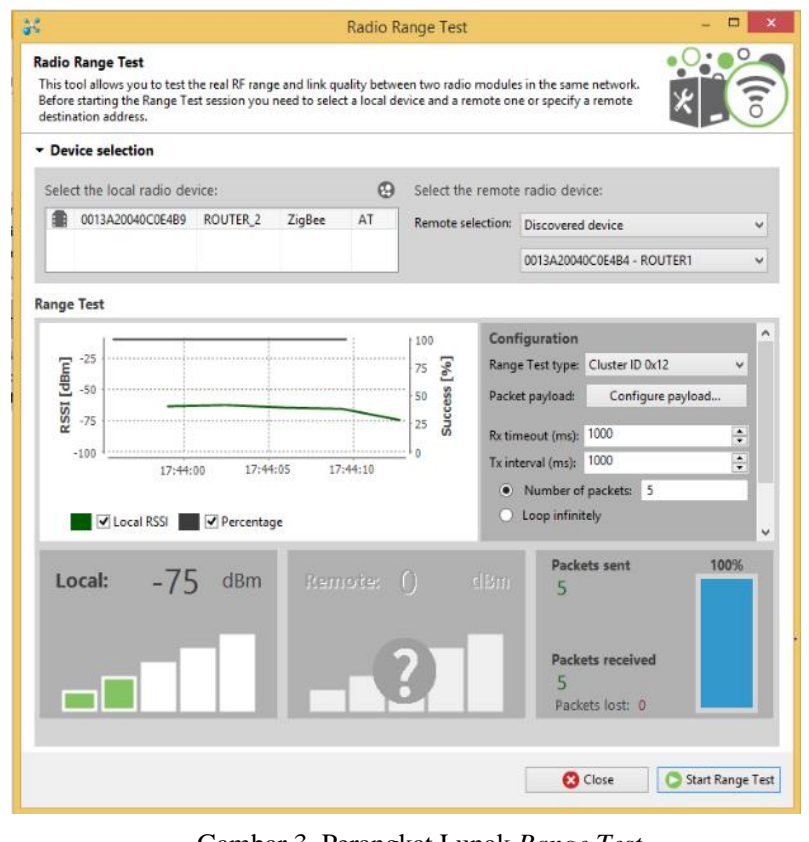

Gambar 3. Perangkat Lunak Range Test

Percobaan dilakukan di Departemen Teknik Elektro dan Informatika dan dilakukan beberapa kali pengujian seperti yang disebutkan di bab pengambilan data. Data yang diambil adalah jarak, kekuatan sinyal, dan tingkat keberhasilan pengiriman data. Modul yang digunakan adalah xbee yang dipasang di arduino UNO seperti yang ditunjukkan oleh Gambar 4.

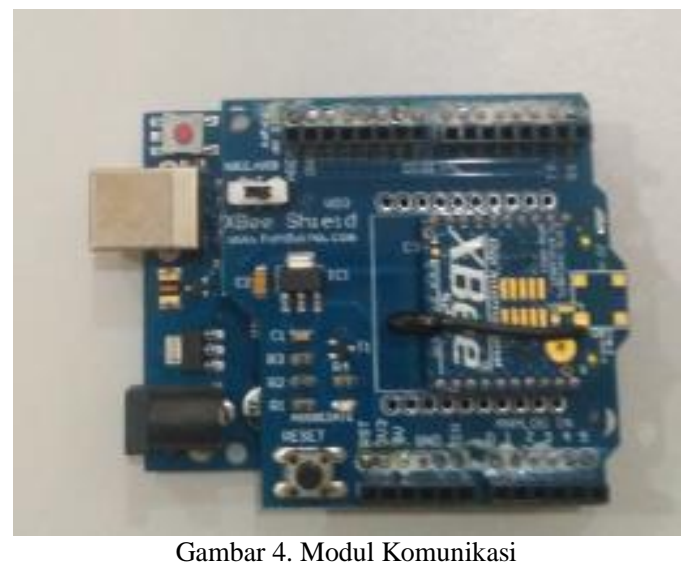

Satu modul dinamakan dengan satu node yang nantinya ini mewakili UAV 1 dan modul lain dinamakan dengan Node 2 yang nantinya akan mewakili UAV 2. Node 1 sebagai referensi yang mengirimkan data dan menerima kembali data yang telah dikirim. Node 2 adalah node yang bergerak, node ini menerima data dari node 1 kemudian dikirim kembali ke node 1 .

\section{HASIL DAN PEMBAHASAN}

Hasil percobaan dengan metode yang sudah dijelaskan di bab sebelumnya ditunjukkan oleh Tabel 2 .

Tabel 2. Data Hasil Percobaan

\begin{tabular}{llllll}
\hline Jarak & Power & Persentase & Data & Data & Data \\
$(\mathrm{m})$ & $(\mathrm{dB})$ & $\begin{array}{l}\text { Keberhasilan } \\
(\%)\end{array}$ & kirim & Terima & Loss \\
& & $(\%)$ & & &
\end{tabular}

\begin{tabular}{cccccc}
\hline 5 & -75 & 100 & 5 & 5 & 0 \\
10 & -73 & 100 & 5 & 5 & 0 \\
15 & -73 & 100 & 5 & 5 & 0 \\
20 & -70 & 100 & 5 & 5 & 0 \\
25 & -84 & 40 & 5 & 2 & 3 \\
30 & -81 & 40 & 5 & 2 & 3 \\
35 & -83 & 100 & 5 & 5 & 0 \\
40 & -84 & 20 & 5 & 1 & 4 \\
45 & -80 & 80 & 5 & 4 & 1 \\
50 & - & 0 & 5 & 0 & 5 \\
\hline
\end{tabular}

Tabel 2. dapat dipecah menjadi dua grafik yang lebih merepresentasikan kekuatan sinyal dan tingkat keberhasilan pengiriman data. Gambar 4 menunjukkan grafik hubungan antara jarak dan kekuatan sinyal. Data kekuatan sinyal di ambil dengan satuan decibel.

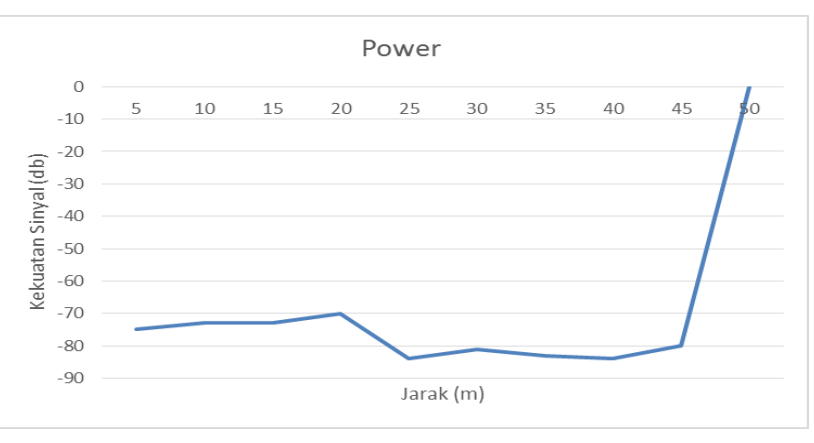

Gambar 4. Grafik Kekuatan sinyal vs jarak

Dilihat dari gambar 3.1, kekuatan sinyal akan menurun seiring dengan bertambahnya jarak antara node 1 dan node 2. Pada jarak 50 perangkat lunak range test tidak dapat melihat kekuatan sinyal sehingga nilainya 0 . Pada jarak ini paket yang dikirim tidak ada yang diterima oleh node 2 . Grafik hubungan antara jarak dan tingkat keberhasilan pengiriman data ditunjukkan oleh Gambar 5.

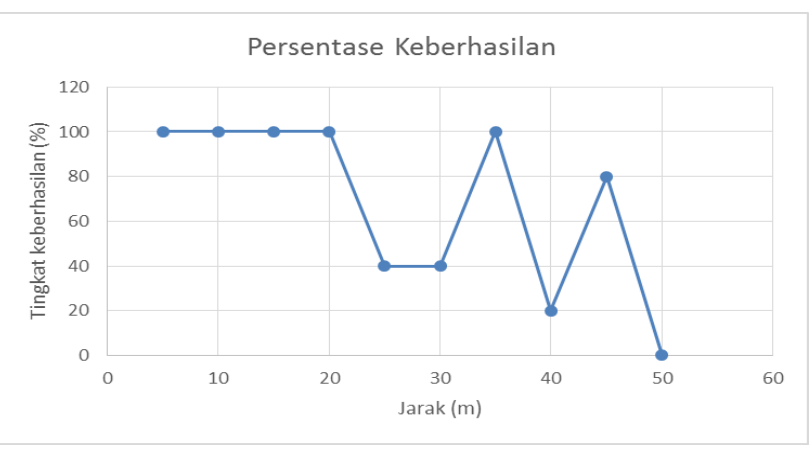

Gambar 5. Grafik tingkat keberhasilan pengiriman data 
Gambar 3.2 menunjukkan bahwa setelah jarak 20m pengiriman data mulai menurun dan mulai tidak stabil. Sehingga dapat disimpulkan bahwa jarak optimal dalam pengiriman data antar UAV adalah $20 \mathrm{~m}$.

\section{KESIMPULAN}

Komunikasi dilakukan menggunakan 2 node. jarak maksimal 50 meter. Pada jarak 30 meter terjadi anomaly data karena tingkat keberhasilan menurun sedangkan pada jarak 35 meter tingkat keberhasilan naik lagi. Semakin jauh jaraknya, kekuatan sinyal semakin berkurang. Jarak antar UAV untuk membentuk formasi adalah 50 meter. Jarak optimal untuk komunikasi antar UAV adalah 10-20 meter.

\section{DAFTAR PUSTAKA}

[1] S. Hayat, E. Yanmaz, and C. Bettstetter, "Experimental analysis of multipoint-to-point UAV communications with IEEE 802.11n and 802.11ac," in 2015 IEEE 26th Annual International Symposium on Personal, Indoor, and Mobile Radio Communications (PIMRC), 2015, pp. 1991-1996, doi: 10.1109/PIMRC.2015.7343625.
[2] F. Mohammed, I. Jawhar, N. Mohamed, and A. Idries, "Towards Trusted and Efficient UAV-Based Communication," in 2016 IEEE 2nd International Conference on Big Data Security on Cloud (BigDataSecurity), IEEE International Conference on High Performance and Smart Computing (HPSC), and IEEE International Conference on Intelligent Data and Security (IDS), 2016, pp. 388393, doi: 10.1109/BigDataSecurity-HPSC-IDS.2016.57.

[3] L. Jingnan, L. Pengfei, and L. Kai, "Research on UAV communication network topology based on small world network model," in 2017 IEEE International Conference on Unmanned Systems (ICUS), 2017, pp. 444-447, doi: 10.1109/ICUS.2017.8278386

[4] X. Sun, R. Blázquez-García, A. García-Tejero, J. M. FernándezGonzález, M. Burgos-García, and M. Sierra-Castañer, "Circular array antenna tor UAV-UAV communications," in 2017 11th European Conference on Antennas and Propagation (EUCAP), 2017, pp. 2025 2028, doi: 10.23919/EuCAP.2017.7928819.

[5] G. Zhang, Q. Wu, M. Cui, and R. Zhang, "Securing UAV Communications via Trajectory Optimization," in GLOBECOM 2017 - 2017 IEEE Global Communications Conference, 2017, pp. 1-6, doi: 10.1109/GLOCOM.2017.8254971.

[6] Z. Xue, J. Wang, Q. Shi, G. Ding, and Q. Wu, "Time-Frequency Scheduling and Power Optimization for Reliable Multiple UAV Communications," IEEE Access, vol. 6, pp. 3992-4005, 2018, doi: 10.1109/ACCESS.2018.2790933. 